OPEN ACCESS

Edited by:

Carlos Roncero,

University of Salamanca Health Care

Complex, Spain

Reviewed by:

George Louis Carlo,

Science and Public Policy Institute

United States

Jonathan Ling,

University of Sunderland,

United Kingdom

${ }^{*}$ Correspondence:

Dai-Jin Kim

kdj922@catholic.ac.k

In Young Choi

iychoi@catholic.ac.kr

Specialty section:

This article was submitted to

Addictive Disorders,

a section of the journal

Frontiers in Psychiatry

Received: 03 September 2018 Accepted: 19 November 2018

Published: 12 December 2018

Citation:

Lee S-J, Choi MJ, Rho MJ, Kim D-J and Choi IY (2018) Factors Affecting

User Acceptance in Overuse of

Smartphones in Mobile Health

Services: An Empirical Study Testing a

Modified Integrated Model in South

Korea. Front. Psychiatry 9:658.

doi: 10.3389/fpsyt.2018.00658

\section{Factors Affecting User Acceptance in Overuse of Smartphones in Mobile Health Services: An Empirical Study Testing a Modified Integrated Model in South Korea}

\author{
Seo-Joon Lee ${ }^{1}$, Mun Joo Choi ${ }^{2,3}$, Mi Jung Rho ${ }^{2,4}$, Dai-Jin Kim ${ }^{5,6 *}$ and In Young Choi ${ }^{2,3,4 *}$ \\ ${ }^{1}$ Research Institute of Health Science, Korea University, Seoul, South Korea, ${ }^{2}$ Department of Medical Informatics, The \\ Catholic University of Seoul, Seoul, South Korea, ${ }^{3}$ Department of Biomedicine \& Health Sciences, College of Medicine, The \\ Catholic University of Korea, Seoul, South Korea, ${ }^{4}$ Catholic Institute for Healthcare Management and Graduate School of \\ Healthcare Management and Policy, The Catholic University of Korea, Seoul, South Korea, ${ }^{5}$ Department of Psychiatry, \\ Addiction Research Institute, Seoul St. Mary's Hospital, College of Medicine, The Catholic University of Korea, Seoul, South \\ Korea, ${ }^{6}$ Department of Psychiatry, Seoul St. Mary's Hospital, College of Medicine, The Catholic University of Korea, Seoul, \\ South Korea
}

Smartphones have become crucial in people's everyday lives, including in the medical field. However, as people become close to their smartphones, this leads easily to overuse. Overuse leads to fatigue due to lack of sleep, depressive symptoms, and social relationship failure, and in the case of adolescents, it hinders academic achievement. Self-control solutions are needed, and effective tools can be developed through behavioral analysis. Therefore, the aim of this study was to investigate the determinants of users' intentions to use m-Health for smartphone overuse interventions. A research model was based on TAM and UTAUT, which were modified to be applied to the case of smartphone overuse. The studied population consisted of 400 randomly selected smartphone users aged from 19 to 60 years in South Korea. Structural equation modeling was conducted between variables to test the hypotheses using a 95\% confidence interval. Perceived ease of use had a very strong direct positive association with perceived usefulness, and perceived usefulness had a very strong direct positive association with behavioral intention to use. Resistance to change had a direct positive association with behavioral intention to use and, lastly, social norm had a very strong direct positive association with behavioral intention to use. The findings that perceived ease of use influenced perceived usefulness, that perceived usefulness influenced behavioral intention to use, and social norm influenced behavioral intention to use were in accordance with prior related research. Other results that were not consistent with previous research imply that these are unique behavioral findings regarding smartphone overuse. This research identifies the critical factors that need to be considered when implementing systems or solutions in the future for tackling the issue of smartphone overuse.

Keywords: smartphone overuse, m-Health, TAM, UTAUT, acceptance 


\section{INTRODUCTION}

\section{Background}

Smartphones have become crucial in our everyday lives, and they affect all sectors from business, to communication, and even to medicine. However, as people become close to their smartphones, they are easily led to engaging in overuse without even acknowledging it. Unfortunately, excessive use sometimes leads to disorders, such as fatigue due to lack of sleep (1), depressive symptoms and social relationship failure (2), and job interruption (3), and in the case of adolescents, it can hinder academic achievement (4). Regarding overuse, the International Classification of Diseases now categorizes "gaming disorder" as a mental illness. This is the first time that the consequences of using digital and mobile devices have been so designated, which makes it more meaningful (5).

In our previous research, we proposed the Smartphone Overdependence Management System (SOMS), which is a management system, and solution for overdependence on smartphones (6). The SOMS was designed to deliver overuse prevention, diagnosis, and treatment services that are based on scientific evidence, which was mostly collected by the developed SOMS smartphone background software application ("app"). The idea was to use the concept of mobile technology that has been extensively applied and widely successful in other healthcare systems (7-11) to aid self-control and support behavioral change in such a way that overuse is controlled.

The neurophysiological impacts of the devices themselves are also important to consider. There have been several studies that show the biological effects of various waveforms emanating from mobile devices, which cause activation of the sympathetic nervous system (SNS) through oxidative stress and other defined mechanisms $(12,13)$. When the SNS is activated, behavioral change is more difficult to achieve, especially when biochemical conversion pathways are initiated (e.g., adrenalin). This means that the device environment is also a barrier to forms of selfcontrol. Thus, there is a difference between information system use regarding a hardwired desktop and accessible laptop and mobile devices. That is, mobile versions have a unique additional problem in that physical bioeffects are caused by the device itself.

The SOMS is currently in the stage of being implemented in a practical way in order to facilitate the remote monitoring of smartphone overuse by users. Most importantly, for successful intervention, factors affecting the user acceptance of such a system or solution must be evaluated beforehand. Specific services can then be developed or modified as effective solutions that best suit the needs of the user. The Technology Acceptance Model (TAM) and Unified Theory of Acceptance and Use

\footnotetext{
Abbreviations: AGFI, Adjusted Goodness-of-Fit Index; App, Application; AVE, Average Variance Extracted; BIU, Behavioral Intention to Use; CFI, Comparative fit index; CR, Construct Reliability; EMR, Electronic Medical Records; GFI, Goodness-of-Fit Index; ICT, Information and Communications Technology; NNFI, Non-Normed Fit Index; NRF, National Research Foundation of Korea; PEoU, Perceived Ease of Use; PS, Perceived Security; PU, Perceived Usefulness; RC, Resistance to Change; RMR, Root mean Square Residual; SAMS, Smartphone Addiction Management System; SD, Standard Deviation; SN, Social Norm; SOMS, Smartphone Overdependence Management System; TAM, Technology Acceptance Model; UTAUT, Unified Theory of Acceptance and Use Technology.
}

of Technology (UTAUT) model have been frequently used to analyze the factors for acceptance, which will be specifically explained in the study design section in the methods.

\section{Research Related to the Acceptance of Smartphone Overuse Monitoring Apps}

The definition of smartphone overuse in this article includes all addictive activities, such as excessive use of the internet, playing games, logging on to messenger services, or accessing virtual communities to the extent that the person neglects positive areas of life, which is similar to the definition of Billieux et al. (14). Although there have been many programs and research studies of interventions for smartphone overuse, there have been few that have used smartphone apps for smartphone overuse intervention. Lin et al. incorporated app-recorded data into the psychiatric criteria for the diagnosis of smartphone addiction and examined the predictive ability of the app-recorded data for the diagnosis of smartphone addiction (15). In addition, Lee et al. proposed a comprehensive information and communications technology (ICT) system called the Smartphone Addiction Management System for smartphone addiction management and verification. The idea was to monitor the users' app usage together with GPS location and internet access location. Other than these few studies, smartphone mobile apps have mostly targeted other risk factors, such as cannabis addiction management (16), smoking cessation (17), and so on.

\section{Goals and Objectives}

Therefore, the aim of this study was to investigate the determinants of the users' intention to use m-Health for smartphone overuse interventions. The research results are expected to identify not only the critical factors to consider when implementing the SOMS, but also to provide successful mainstream guidelines for future systems or solutions that tackle the issue of smartphone overuse, for example, apps that are being released that have screen-time monitors.

\section{METHODS}

\section{Study Design}

The research model of this paper was fundamentally based on the TAM and UTAUT models. The TAM is a widely accepted and influential model that predicts users' perceptions or acceptance of information system use (18-20). The UTAUT is the latest derivative of the TAM. The TAM has been constantly developed by researchers, which has led to the creation of many variants, such as the Extended TAM, Psychosocial TAM, and Integrated TAM (21).

Although this research was based on the TAM and UTAUT, we modified these models by converging, excluding, or including some important variables that were identified as appropriate in the case of smartphone overuse intervention by smartphone apps, as shown in Figure 1.

The TAM basically proposes two main factors that determine the users' behavioral intention to use (BIU), which are its perceived usefulness (PU), and perceived ease of use (PEoU). It was also acknowledged by the researchers that, at times, PU acts 


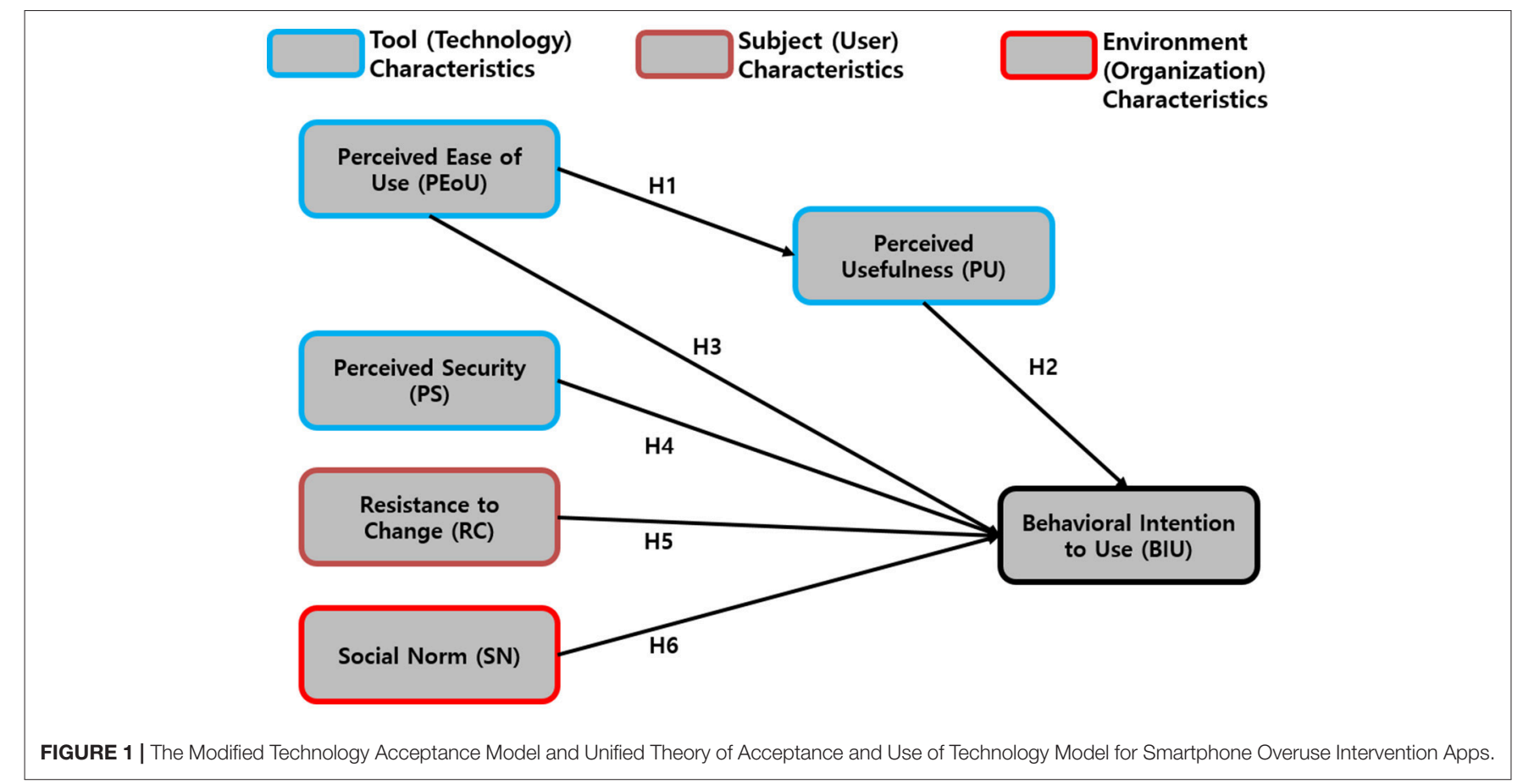

as a mediator between PEoU and BIU; thus, this was taken into account.

In this model, perceived security (PS) was added, since personal security issues in network services have been a threat to many services including in the field of healthcare, which obtains sensitive private information. Altogether, PU, PEoU, and PS comprise the tool characteristics (which represent the technology).

Other factors, such as resistance to change (RC) and social norm (SN), were added, with each representing the subjects' characteristics (representative of the users) and environmental characteristics. The research hypotheses were tested in relation to the model proposed above and they are shown in Table $\mathbf{1 .}$

\section{Studied Population and Sample}

The studied population consisted of 400 randomly selected smartphone users aged from 19 to 60 years who were from a social survey institution panel (which was evenly pooled domestically), which was to be extrapolated to the smartphone users of South Korea. Those who had provided written informed consent prior to the survey were accepted. Participants were briefly informed about the SOMS before the survey (shown in the first page of our survey). Participants who were not adults were excluded because of the possibility that they would not understand the research. A brief but sufficient explanation was given about the research before the survey. Participants older than 60 years of age were excluded because they are not accustomed to smartphones.

The size of the sample population was selected based on the following criteria. According to the July 2017 statistics, $\sim 9$ out of 10 adults use smartphones (population $N=37,454,121$ ). For reliability within the $95 \%$ confidence interval, the appropriate
TABLE 1 | Summary of the proposed research hypotheses.

\begin{tabular}{|c|c|c|}
\hline Hypothesis & & $\begin{array}{l}\text { Models used to test the } \\
\text { hypotheses }\end{array}$ \\
\hline $\mathrm{H} 1$ & $\begin{array}{l}\text { PEoU has a positive direct effect } \\
\text { on PU }\end{array}$ & \multirow{6}{*}{$\begin{array}{l}\text { Original TAM, Extended } \\
\text { TAM, Psychosocial TAM, } \\
\text { Integrated TAM, UTAUT }\end{array}$} \\
\hline $\mathrm{H} 2$ & $\begin{array}{l}\text { PU has a positive direct effect on } \\
\text { BIU }\end{array}$ & \\
\hline $\mathrm{H} 3$ & $\begin{array}{l}\text { PEoU has a positive direct effect } \\
\text { on BIU }\end{array}$ & \\
\hline $\mathrm{H} 4$ & $\begin{array}{l}\text { PS has a positive direct effect on } \\
\text { BIU }\end{array}$ & \\
\hline $\mathrm{H} 5$ & $\begin{array}{l}\text { RC has a positive direct effect on } \\
\text { BIU }\end{array}$ & \\
\hline $\mathrm{H} 6$ & $\begin{array}{l}\text { SN has a positive direct effect on } \\
\text { BIU }\end{array}$ & \\
\hline
\end{tabular}

H, hypothesis; TAM, technology acceptance model; UTAUT, unified theory of acceptance and use of technology.

recommended sample size was 385 . Considering the possibility of missing values, we recruited 15 more people, adding up to a total of 400 .

Only participants who used smartphones for at least $1 \mathrm{~h}$ a day were selected. Among them, half $(n=200)$ were selected based on the condition that they had the experience of using similar smartphone usage monitoring/measuring app(s). The other half $(n=200)$ were selected based on the condition that they did not have any experience of using any similar smartphone usage monitoring/measuring app(s). These groups were evenly selected to prevent a bias of friendliness toward smartphone apps. 
다음은 스마트폰 과의존 모니터링 시스템이 얼마나 쉽게 이해되는 다음은 스마트폰 과의존 모니터링 시스템이 얼마나 유용하다고 생

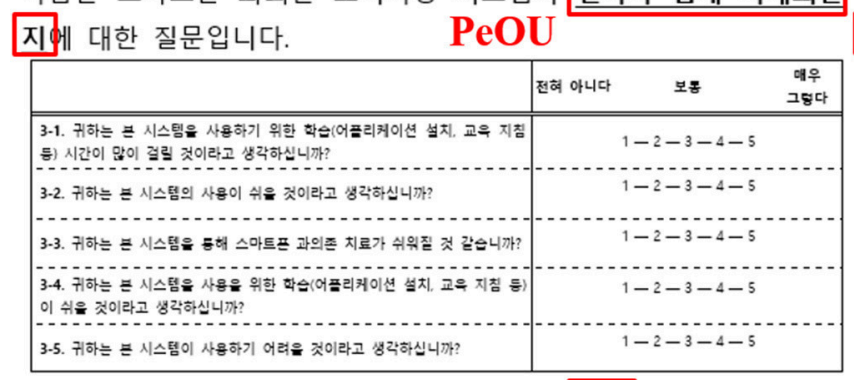
각되는지에 대한 질문입니다. $\quad \mathrm{PU}$

다음은 스마트폰 과의존 모니터링 시스템의 보안에 대한 질문입니

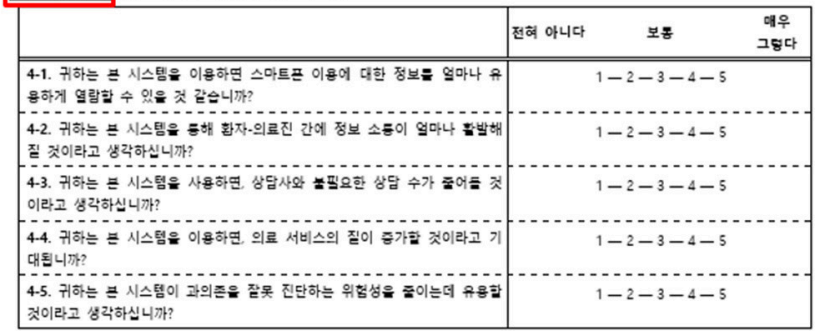

다. PS

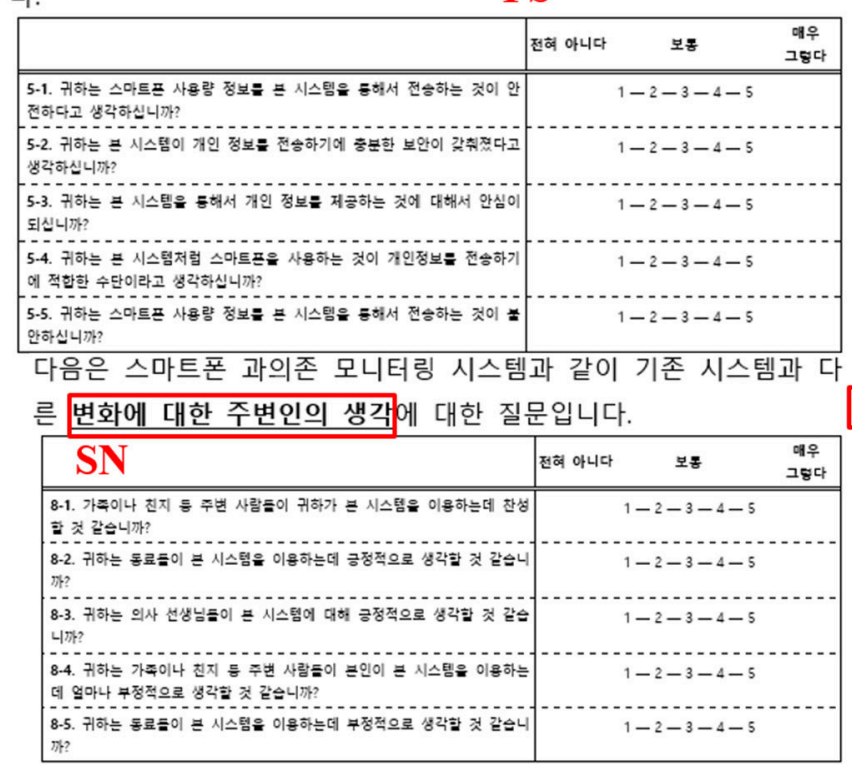

다음은 스마트폰 과의존 모니터링 시스템과 같이 기존 시스템과 다 른 변화에 대한 개인적인 생객에 대한 질문입니다.

\begin{tabular}{|c|c|c|c|}
\hline $\mathbf{R C}$ & 전형 아니다 & 보퐁 & $\begin{array}{l}\text { 대우 } \\
\text { 그황다 }\end{array}$ \\
\hline $\begin{array}{l}\text { 7-1. 거하는 정보튼신 기숨은 이용한 븐 시스텀 사용어 대한 거부감이 있으 } \\
\text { 신니까? }\end{array}$ & \multicolumn{3}{|c|}{$1-2-3-4-5$} \\
\hline 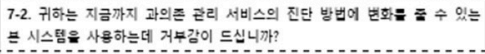 & \multicolumn{3}{|c|}{$1-2-3-4-5$} \\
\hline 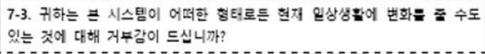 & \multicolumn{3}{|c|}{$1-2-3-4-5$} \\
\hline 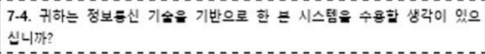 & \multicolumn{3}{|c|}{$1-2-3-4-5$} \\
\hline 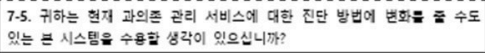 & \multicolumn{3}{|c|}{$1-2-3-4-5$} \\
\hline
\end{tabular}

다음은 본 스마트폰 과의존 모니터링 시스템을 얼마나 사용할 의향이 있 는지에 대한 질문입니다.

\begin{tabular}{|c|c|c|c|}
\hline & 전혀 아니다 & 보동 & $\begin{array}{l}\text { 애우 } \\
\text { 그횽다 }\end{array}$ \\
\hline 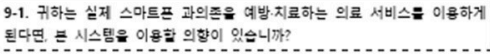 & \multicolumn{3}{|c|}{$1-2-3-4-5$} \\
\hline $\begin{array}{l}\text { 9-2. 귀하는 기회가 된다면, 주변인틀어거 큭 시스텀을 추천할 의항이 있슨ㄴ } \\
\text { 까? }\end{array}$ & \multicolumn{3}{|c|}{$1-2-3-4-5$} \\
\hline 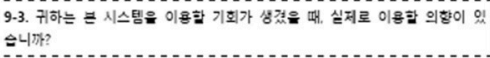 & \multicolumn{3}{|c|}{$1-2-3-4-5$} \\
\hline 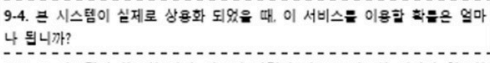 & \multicolumn{3}{|c|}{$1-2-3-4-5$} \\
\hline $\begin{array}{l}\text { 9.5. 른 시스팀이 상융화 되면, 사융과 관런된 비용을 지경한 의사가 있으신 } \\
\text { 니까? }\end{array}$ & \multicolumn{3}{|c|}{$1-2-3-4-5$} \\
\hline
\end{tabular}

FIGURE 2 | Screenshots of the Survey Taken Regarding PeOU, PU, PS, RC, SN, and BIU.

This research study's procedures were performed in accordance with the Declaration of Helsinki. The Institutional Review Board of the Catholic University of South Korea, St. Mary's Hospital (MC17QESI0076), approved the study.

\section{Variables}

In this research, the acceptance (or BIU) of a smartphone overuse monitoring app among smartphone users was the dependent latent variable. The term "smartphone overuse monitoring system" was defined at the beginning of the questionnaire. All questions, except for those that required shortanswer questions or socio-demographic information, captured responses through a five-point scale. This five-point Likert scale ranged from "strong negative," "negative," "neutral," "strong," to "strong positive." Five survey items were measured for each of the PEoU, PU, PS, RC, SN, and BIU latent variables based on prior TAM- and UTAUT-related research (2124), but they were modified to suit the current research study's theme. Screenshots of our survey are presented in Figure 2 (the Korean to English translation is shown in red).
The PEoU items included "Do you think it will take long to learn the smartphone overuse monitoring system?" (PEoU1), "Do you think that it will be easy to use such a system?" (PEoU2), "Do you think that smartphone overuse treatment will become easier due to this system?" (PEoU3), "Do you think that learning how to use this system will be easy?" (PEoU4), and "Do you think that this system will be hard to use?” (reverse question, PEoU5).

The PU items included "How useful do you think this system will be when learning to control the use of smartphones?" (PU1), "Do you think that doctors and patients will become closer during overuse treatment due to this system?" (PU2), "Do you think that by using this system, needless overuse consulting sessions will decrease?" (PU3), "Do you think that by using this system, the quality of service regarding smartphone overuse treatment will improve?" (PU4), and "Do you think that this system will contribute to reducing misdiagnosis of actual smartphone usage time?" (PU5).

The PS items included "Do you think it is safe to transfer your personal smartphone usage information via this system?" (PS1), "Do you think that this system has sufficient security to transmit personal information?" (PS2), "Would you feel safe when transmitting personal information via this 
system?" (PS3), "Do you think that using smartphones is a reliable way to transmit personal information?" (PS4), and "Would you feel uncomfortable when transmitting smartphone usage information via this system?" (reverse question, PS5) (Supplementary Table 1).

The RC items included "Do you find this ICT applied system repulsive?" (RC1), "Do you find this system, which may change the current method of diagnosing smartphone overuse, repulsive?" (RC2), "Do you find this system, which could bring some change to your way of life, repulsive?" (RC3), "Are you willing to accept this ICT applied system?" (reverse question, RC4), and "Are you willing to accept this system, which is expected to change the current method of diagnosing smartphone overuse?" (RC5).

The SN items included "Do you think your family or friends will agree with you using this system?" (SN1), "Do you think your friends or coworkers will think positively about you using this system?" (SN2), "Do you think that doctors will be positive about this system?" (SN3), "How negatively do you think your family or friends will think about you using this system?" (SN4), and "How negatively do you think your friends or coworkers will think about you using this system?” (SN5).

Lastly, the BIU items included "If you were to use a smartphone overuse prevention or treatment service, would you consider using this system?" (BIU1), "If the opportunity arises, would you recommend this system?" (BIU2), "If the opportunity arises for you to use this system, would you use it?" (BIU3), "If this system was implemented as an actual service, what are the chances that you will use it?" (BIU4), and "If this system was implemented as an actual service, would you be willing to pay the right amount of fees to use this system's service?" (BIU5).

\section{Statistical Analyses}

Descriptive statistical analysis was conducted to summarize the overall socio-demographic results. Then, correlation analysis was performed to measure the magnitude of the associations between the independent latent variables and the dependent latent variable for each hypothesis (i.e., $\mathrm{H} 1, \mathrm{H} 2, \mathrm{H} 3, \mathrm{H} 4, \mathrm{H} 5$, and H6). Structural equation modeling (SEM) was also conducted to test each hypothesis. All statistical analyses were performed using SAS 9.3 with a $95 \%$ confidence interval. All values were rounded up to the second decimal place.

\section{RESULTS}

\section{Socio-Demographic Results}

The socio-demographic results are shown in Table 2. Fifty percent of the participants were men $(n=200)$ and $50 \%$ were women $(n=200)$. Forty percent were 19 to 29 years old $(n=$ $160)$, $40 \%$ were 30 to 39 years old $(n=160)$, and $20 \%$ were over $40(n=80)$. The most used app was SNS, with a percentage of $48.75(n=195)$.

A plurality of respondents lived in Seoul (32\%, $n=128)$. Most respondents were at least graduate school students $(63.25 \%, n=$ $253)$ and the most common occupation was white-collar $(40.25 \%$, $n=161$ ). The most common monthly salary group was 3.7 thousand dollars or more per month $(45 \%, n=180)$. Regarding
TABLE 2 | Socio-demographic results of the participants.

\begin{tabular}{|c|c|c|c|}
\hline Characteristics & & $N$ & Percentage \\
\hline \multirow[t]{2}{*}{ Gender } & Male & 200 & 50.0 \\
\hline & Female & 200 & 50.0 \\
\hline \multirow[t]{3}{*}{ Age group (years) } & $19-29$ & 160 & 40.0 \\
\hline & $30-39$ & 160 & 40.0 \\
\hline & Over 40 & 80 & 20.0 \\
\hline \multirow{7}{*}{$\begin{array}{l}\text { Most Used App During } \\
\text { the Past Year }\end{array}$} & SNS & 195 & 48.75 \\
\hline & Web Surfing & 104 & 26.0 \\
\hline & Game & 33 & 8.25 \\
\hline & Entertainment & 28 & 7.0 \\
\hline & Shopping & 10 & 2.5 \\
\hline & Taking Photos & 6 & 1.5 \\
\hline & Others & 23 & 6 \\
\hline \multirow[t]{6}{*}{ Location $^{\mathrm{b}}$} & Seoul & 128 & 32.0 \\
\hline & Gyeonggi/Incheon & 127 & 31.75 \\
\hline & Chungcheong & 27 & 6.75 \\
\hline & Jeonla & 26 & 6.5 \\
\hline & Gyeongsang & 82 & 20.5 \\
\hline & Others & 10 & 2.5 \\
\hline \multirow[t]{4}{*}{ Education } & $\begin{array}{l}\text { Middle School or } \\
\text { Lower }\end{array}$ & 43 & 10.75 \\
\hline & High School & 65 & 16.25 \\
\hline & Graduate School & 253 & 63.25 \\
\hline & Ph.D. or Above & 39 & 9.75 \\
\hline \multirow[t]{6}{*}{ Occupation $^{c}$} & White-Collar & 161 & 40.25 \\
\hline & $\begin{array}{l}\text { Administrative } \\
\text { Position }\end{array}$ & 25 & 6.25 \\
\hline & Service & 34 & 8.5 \\
\hline & $\begin{array}{l}\text { Technical } \\
\text { Professional }\end{array}$ & 48 & 12.0 \\
\hline & Student & 60 & 15.0 \\
\hline & Others & 72 & 18.0 \\
\hline \multirow{4}{*}{$\begin{array}{l}\text { Monthly Salary (U.S. } \\
\text { Dollars) }\end{array}$} & $<1.8$ Thousand & 65 & 16.25 \\
\hline & $\begin{array}{l}\text { 1.8 Thousand } \leq \text { to } \\
<2.7 \text { Thousand }\end{array}$ & 82 & 20.5 \\
\hline & $\begin{array}{l}2.7 \text { Thousand } \leq \text { to } \\
<3.7 \text { Thousand }\end{array}$ & 73 & 18.25 \\
\hline & 3.7 Thousand $\leq$ & 180 & 45.0 \\
\hline \multirow{3}{*}{$\begin{array}{l}\text { Perceived } \\
\text { Socio-Economic Status }\end{array}$} & Low & 160 & 40.0 \\
\hline & Middle & 230 & 57.5 \\
\hline & High & 10 & 2.5 \\
\hline Total & & 400 & 100 \\
\hline
\end{tabular}

a Other apps included those for health, diet, transportation, finance, weather, and so on.

${ }^{b}$ Other locations included Gangwon and Jeju.

${ }^{c}$ Other occupations included agricultural and blue-collar.

${ }^{d}$ Approximate value converted from Korean won to U.S. dollars.

the perceived socio-economic-status, middle class was the most common $(57.5 \%, n=230)$.

\section{Variables Measured and Psychometric Properties}

Based on the Kaiser-Meyer-Olkin test, confirmatory factor analysis was not acceptable for some theoretical constructs; 
therefore, they were excluded. Only acceptable theoretical constructs were chosen, which are shown in Table 3 (an average of 0.88 ). The Bartlett's test results also showed a chi-square value of 4133.91, with 231 degrees of freedom, and a $p$-value lower than 0.0001 . In addition, the Cronbach's alpha values were acceptable for all constructs among the acceptable constructs of the confirmatory factor analysis (0.75 to 0.88 ), except for PEoU (0.65); however, this was adequate based on past findings (25). Table 3 shows the mean, standard deviation $(S D)$, Cronbach's alpha, factor loading, construct reliability, and average variance extracted of all the constructs.

TABLE 3 | Theoretical Constructs and Psychometric Properties of the Measures.

\begin{tabular}{|c|c|c|c|c|c|}
\hline Construct & Mean $\pm S D$ & $\begin{array}{l}\text { Cronbach's } \\
\text { alpha }\end{array}$ & $\begin{array}{l}\text { s Factor } \\
\text { loading }\end{array}$ & $\begin{array}{l}\text { Construct } \\
\text { reliability }\end{array}$ & $\begin{array}{l}\text { Average } \\
\text { variance } \\
\text { extracted }\end{array}$ \\
\hline $\begin{array}{l}\text { Perceived } \\
\text { ease of use }\end{array}$ & & 0.65 & & 0.722 & 0.474 \\
\hline PEoU2 & $3.35 \pm 0.84$ & & 0.75 & & \\
\hline PEoU4 & $3.2 \pm 0.81$ & & 0.692 & & \\
\hline PEoU5 & $2.49 \pm 0.88$ & & 0.433 & & \\
\hline $\begin{array}{l}\text { Perceived } \\
\text { usefulness }\end{array}$ & & 0.82 & & 0.861 & 0.556 \\
\hline PU1 & $3.29 \pm 0.83$ & & 0.591 & & \\
\hline PU2 & $3.31 \pm 0.86$ & & 0.708 & & \\
\hline PU3 & $3.21 \pm 0.87$ & & 0.624 & & \\
\hline PU4 & $3.21 \pm 0.83$ & & 0.771 & & \\
\hline PU5 & $3.25 \pm 0.88$ & & 0.749 & & \\
\hline $\begin{array}{l}\text { Perceived } \\
\text { security }\end{array}$ & & 0.87 & & 0.888 & 0.666 \\
\hline PS1 & $2.68 \pm 0.92$ & & 0.734 & & \\
\hline PS2 & $2.48 \pm 0.92$ & & 0.867 & & \\
\hline PS3 & $2.28 \pm 0.98$ & & 0.843 & & \\
\hline PS4 & $2.54 \pm 0.95$ & & 0.743 & & \\
\hline $\begin{array}{l}\text { Resistance to } \\
\text { change }\end{array}$ & & 0.75 & & 0.776 & 0.635 \\
\hline $\mathrm{RC} 1$ & $2.5 \pm 0.95$ & & 0.734 & & \\
\hline $\mathrm{RC} 3$ & $2.56 \pm 0.89$ & & 0.816 & & \\
\hline Social norm & & 0.77 & & 0.844 & 0.647 \\
\hline SN1 & $3.09 \pm 0.77$ & & 0.729 & & \\
\hline SN2 & $3.12 \pm 0.76$ & & 0.855 & & \\
\hline SN3 & $3.21 \pm 0.83$ & & 0.596 & & \\
\hline $\begin{array}{l}\text { Behavioral } \\
\text { intention to } \\
\text { use }\end{array}$ & & 0.88 & & 0.895 & 0.632 \\
\hline BIU1 & $3.13 \pm 0.94$ & & 0.818 & & \\
\hline BIU2 & $3.13 \pm 0.87$ & & 0.779 & & \\
\hline BIU3 & $3.18 \pm 0.9$ & & 0.844 & & \\
\hline BIU4 & $2.94 \pm 0.94$ & & 0.803 & & \\
\hline BIU5 & $2.41 \pm 1.03$ & & 0.635 & & \\
\hline
\end{tabular}

$S D$, standard deviation; PEOU, perceived ease of use; PU, perceived usefulness; PS, perceived security; $R C$, resistance to change; $S N$, social norm; BIU, behavioral intention to use.

\section{Correlation Analysis Between the Theoretical Constructs}

The correlation analysis between all the theoretical constructs is shown in Table 4. All results were statistically significant within a $95 \%$ confidence interval. The constructs' correlations ranged from 0.69 to 0.82 .

\section{Fit Indices of the Measurement Models and Their Acceptable Ranges}

The measurement models' fit indices, including the acceptable thresholds, are shown in Table 5. The chi-square/degrees of freedom $\left(\chi^{2} / d f\right)$ was 2.895 ( $\leq 3.00$ recommended), the goodness-of-fit index (GFI) was 0.884 ( $\geq 0.90$ recommended), the adjusted GFI index (AGFI) was 0.851 ( $\geq 0.90$ recommended), the non-normed fit index (NNFI) was $0.865 \quad(\geq 0.90$ recommended), the comparative fit index was 0.906 ( $\geq$ 0.90 recommended), and the root mean square residual was 0.063 ( $\leq 0.08$ recommended). Although the values of the GFI, AGFI, and NNFI were slightly lower than recommended, it was concluded that all fit indices were acceptable and supported a reasonable fit assumption.

\section{Measurement Model and Structural Model}

The results of the SEM are presented in this section. All constructs were in accordance with the results shown in Table 3. All socio-demographic information was adjusted. Figure 3 shows the results of the structural model. The findings supported $\mathrm{H} 1, \mathrm{H} 2, \mathrm{H} 3, \mathrm{H} 5$, and H6, but not H4. Therefore, PEoU had a very strong direct positive association with PU (H1, positive correlation), and PU had a very strong direct positive association with $\mathrm{BIU}$ (H2, positive correlation). However, in the case of $\mathrm{H} 3$, PEoU had a direct negative association with BIU, rather than a positive association ( $\mathrm{H} 3$, negative correlation). RC had a direct positive association with BIU (H5, positive correlation) and, lastly, SN had a very strong direct positive association with BIU (H6, positive correlation).

\section{DISCUSSION}

\section{Comparison With Prior Work}

Although examined in other fields (and considering the fact that factor analysis of the perception of smartphone overuse

TABLE 4 | Correlation analysis between the theoretical constructs.

\begin{tabular}{lcccccc}
\hline & PEOU & PU & BIU & PS & RC & SN \\
\hline PEOU & $\mathbf{0 . 6 8 9}$ & & & & & \\
PU & 0.553 & $\mathbf{0 . 7 4 6}$ & & & & \\
BIU & 0.317 & 0.637 & $\mathbf{0 . 7 9 5}$ & & & \\
PS & 0.174 & 0.408 & 0.436 & $\mathbf{0 . 8 1 6}$ & & \\
RC & 0.243 & 0.258 & 0.391 & 0.214 & $\mathbf{0 . 7 9 7}$ & \\
SN & 0.425 & 0.533 & 0.704 & 0.451 & 0.416 & $\mathbf{0 . 8 0 5}$
\end{tabular}

PEOU, perceived ease of use; $P U$, perceived usefulness; BIU, behavioral intention to use $P S$, perceived security; $R C$, resistance to change; $S N$, social norm. Bold values represents Pearson's Correlation Coefficients. 
monitoring apps is scarce), the result that Perceived Ease of Use is a significant determinant of Perceived Usefulness is consistent with the findings of numerous previous research studies $(19,26-$ 28). In accordance with the discussion in these studies, it can be concluded that, in the case of smartphone overuse monitoring apps, the friendliness of the user interface can critically affect the treatment compliance among users.

In addition, the current study's results that show that Perceived Usefulness is a strong and significant determinant of Behavioral Intention to Use are consistent with related research. Deng et al. (22) found that perceived value had significant effects on both attitudes toward mobile health services and behavioral intention. When considering physicians as users, Gagnon et al. (21) found that, in all of their proposed relevant models, Perceived Usefulness had a significant influence on Behavioral Intention to Use. Similarly, Hung et al. (29) further investigated if Perceived Usefulness could even indirectly influence Behavioral Intention to Use by positively influencing attitudes. It can be inferred that promoting a positive attitude toward e-health technology can enhance users' adaptation to apps that monitor overuse.

The most interesting new finding concerned the relationship between Perceived Ease of Use and Behavioral Intention to Use.

TABLE 5 | Fit indices of the measurement models and their acceptable ranges.

\begin{tabular}{lcc}
\hline Model-fit index & Recommended value & Scores \\
\hline Chi-square/degrees of freedom & $\leq 3.00$ & 2.895 \\
Goodness-of-fit index & $\geq 0.90$ & 0.884 \\
Adjusted goodness-of-fit index & $\geq 0.90$ & 0.851 \\
Non-Normed fit index & $\geq 0.90$ & 0.865 \\
Comparative fit index & $\geq 0.90$ & 0.906 \\
Root mean square residual & $\leq 0.08$ & 0.063
\end{tabular}

The important point here was that, although this research is congruent with other research reporting that Perceived Ease of Use is a significant determinant of Behavioral Intention to Use $(21,30)$, the influence was negative rather than positive. This may be considered a contradictory result to some prior research, including Melas et al. who stated that users tend to look for easy tools (19) rather than complex ones. It can be inferred from these results that users will no longer simply show intention to use an app because it is easy to use. That is, having a utility or structure that is too simplistic may hinder the intention to use it, possibly due to lowered credibility that the app is sufficiently professional to take care of one's health. This may be because recent users have increased smartphone adaptability and usage, and that healthcare users have especially become much smarter with using apps than in the past. Consequently, healthcare-related smartphone app services should appeal to the users in terms of their usefulness in order to be accepted as a reliable tool that is expected to contribute to healthcare.

The results indicating that Perceived Security had no significant influence on Behavioral Intention to Use contradict some previous research. Cimperman et al. (23) emphasized that Perceived Security is one of the three key factors that influence acceptance, it can be inferred from our findings that this is not applicable to the logic of accepting smartphone overuse monitoring apps. Ebert et al. (24) also stated that Perceived Security significantly affects acceptance of internetbased mental health interventions. These contradictions may have been caused by the following issues. First, our results could indicate a new approach that, in the case of smartphone overuse monitoring apps, the data security issues do not significantly override their desire to overcome their overuse. Second, Ketelaar (31) mentioned that, in a fundamental sense, the users' earlier position on the adoption curve and their smartphone literacy (which is congruent with discussions held regarding the effect of

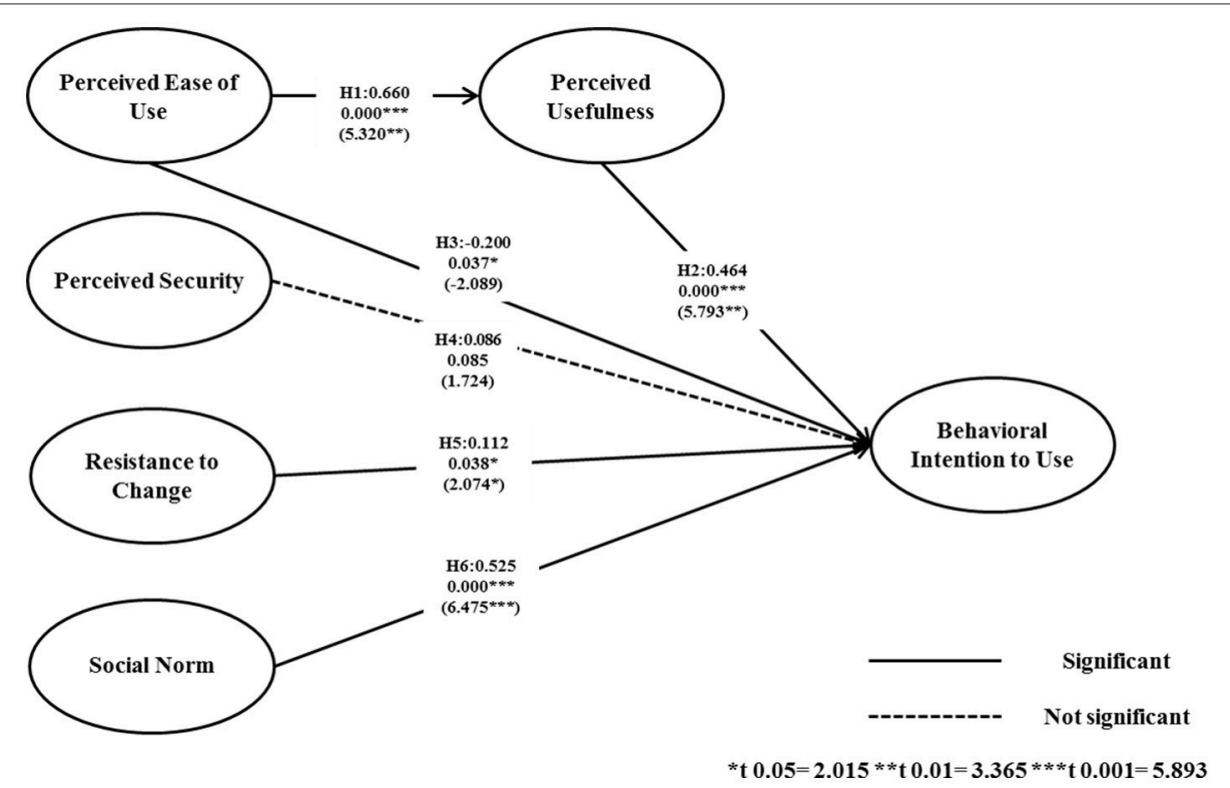

FIGURE 3 | Structural Model and Standardized Regression Coefficients. H: hypothesis. 
Perceived Ease of Use on Behavioral Intention to Use) decreases the strength of the connection between privacy concerns and attitude.

Another interesting point is that Resistance to Change had a positive significant effect on Behavioral Intention to Use, which is not consistent with prior research. In terms of smartphone apps vs. electronic medical records, William (32) found that resistance to change had an indirect negative significant effect on Behavioral Intention to Use. However, the author's results may have been different if the direct influence was investigated. Deng et al. (22) also proved that Resistance to Change had a negative and significant effect on the Behavioral Intention to Use mobile services among middle-aged people, which contrasts with our results. Somewhat similar results to Deng et al. were found among older groups of people, in which Resistance to Change had no significant effect on Behavioral Intention to Use. Despite the strong rejection of change, users of healthcare apps would still choose to use them in order to increase their well-being. In addition, considering that our participants were users that were already considerably accustomed to using smartphones (note that, as explained in the methods section, only users who have smartphone usage experience were selected), their characteristics indicate that they are already negative toward Resistance to Change, and that it was only not shown in the statistical results. This is why their Behavioral Intention to Use was positive despite the results. This can also be inferred from the $\beta$ value, which was the lowest (2.074) of all the statistically significant $\beta$ values. Lastly and most importantly, Resistance to Change is very possibly influenced the most by the neurophysiological impacts of the emissions from the devices themselves. Therefore, without adequate control, it is not clear what that means relative to the other variables.

Social Norm had a significant effect on Behavioral Intention to Use, which is consistent with prior findings in related fields $(21,23,24)$. Additionally, Hsiao and Chen (33) pointed out that social influence was one of the critical factors influencing intention to use. Although a narrower concept, Hung et al. (29) also indicated that co-workers' viewpoints positively influenced intention to use. Therefore, the finding that facilitating the support of the families or friends of the users helps to boost the users' intention to use should be consistently considered from the early education/facilitation stage of the smartphone overuse monitoring system until the end of the intervention.

\section{CONCLUSIONS}

The objective of this study was to investigate the factors influencing the users' intention to use a smartphone overuse monitoring app for smartphone overuse prevention and treatment interventions. The findings regarding Perceived Ease of Use influencing Perceived Usefulness, Perceived Usefulness influencing Behavioral Intention to Use, and Social Norm influencing Behavioral Intention to Use were in accordance with previous related research.

The core findings regarding the negative influence of Perceived Ease of Use on Behavioral Intention to Use, Perceived Security's non-significant influence on Behavioral Intention to Use, and Resistance to Change's positive influence on Behavioral Intention to Use were in contrast to some meaningful related research. These can be considered to be unique findings related to the smartphone overuse monitoring app intervention, which opens some discussion that requires future research.

One limitation of this research is that the population did not include adolescents, who are known to be heavy smartphone users who are particularly susceptible to overusing these devices. Another shortcoming is that the neurophysiological impacts of the devices themselves were not adequately controlled.

Future research is being planned that actually applies the findings of this study and implements the SOMS to investigate health-related outcomes. Future research should also include further investigation of the difference in perception between genders regarding the acceptance of the app, since the possibility of a difference has been suggested in previous research (34).

The research results not only identify the critical factors to consider when implementing the SOMS, they are also expected to provide successful mainstream guidelines for future systems or solutions that tackle the issue of smartphone overuse with apps. For example, there are now many apps that are being released that have screen-time monitors. This is a practically useful aspect, especially when considering Apple's CEO Tim Cook's recent quote that even he uses his smartphone too much. Most importantly, our unique points are envisioned to provide intensive insights for broadening knowledge about technology acceptance in the field of e-addictology (35).

\section{AUTHOR CONTRIBUTIONS}

S-JL designed the study and manuscript. MC collected data and conducted statistical analysis. MR participated in study. D-JK and IC co-corresponded and drove the research project.

\section{ACKNOWLEDGMENTS}

This research was supported by the Brain Research Program through the National Research Foundation of Korea (NRF) founded by the Ministry of Science, ICT \& Future Planning, NRF-2014M3C7A1062893 and NRF-2015M3C7A1064796.

\section{SUPPLEMENTARY MATERIAL}

The Supplementary Material for this article can be found online at: https://www.frontiersin.org/articles/10.3389/fpsyt. 2018.00658/full\#supplementary-material 


\section{REFERENCES}

1. Pavia L, Cavani P, Di Blasi M, Giordano C. Smartphone Addiction Inventory (SPAI): Psychometric properties and confirmatory factor analysis. Comput Human Behav. (2016) 63:170-8. doi: 10.1016/j.chb.2016. 05.039

2. Seo DG, Park Y, Kim MK, Park J. Mobile phone dependency and its impacts on adolescents' social and academic behaviors. Comput Human Behav. (2016) 63:282-92. doi: 10.1016/j.chb.2016.05.026

3. Vaisman A, Wu RC. Analysis of smartphone interruptions on academic general internal medicine wards. Appl Clin Inform. (2017) 8:1-11. doi: 10.4338/ACI-2016-08-RA-0130

4. Hawi NS, Samaha M. To excel or not to excel: Strong evidence on the adverse effect of smartphone addiction on academic performance. Comput Educ. (2016) 98:81-89. doi: 10.1016/j.compedu.2016.03.007

5. Rumpf HJ, Achab S, Billieux J. Including gaming disorder in the ICD-11: the need to do so from a clinical and public health perspective. J Behav Addict. (2018) 7:556-61. doi: 10.1556/2006.7.2018.59

6. Lee SJ, Rho MJ, Yook IH, Park S-H, Jang K, Park B-J, et al. Design, development and implementation of a smartphone overdependence management system for the self-control of smart devices. Appl. Sci. (2016) 6:440. doi: 10.3390/app6120440

7. Madhushri P, Dzhagaryan A, Jovanov E, Milenkovic A. An mHealth tool suite for mobility assessment. Information (2016) 7:47 doi: 10.3390/info7030047

8. Ford JH, Alagoz E, Dinauer S, Johnson KA, Pe-Romashko K, Gustafson DH. Successful organizational strategies to sustain use of A-CHESS: a mobile intervention for individuals with alcohol use disorders. J Med Internet Res. (2015) 17:e201. doi: 10.2196/jmir.3965

9. Park HS, Cho H, Kim HS. Development of a multi-agent m-health application based on various protocols for chronic disease self-management. J Med Syst. (2016) 40:36. doi: 10.1007/s10916-015-0401-5

10. Prance RJ, Fatoorechi M, Prance H. Detection of movement, gait \& bio-signals for e-Health \& home care. Biomed Eng Tech. (2014) 59:S815-7.

11. Quanbeck A, Gustafson DH, Marsch LA, Chih MY, Kornfield R, McTavish F, et al. Implementing a mobile health system to integrate the treatment of addiction into primary care: a hybrid implementation-effectiveness study. $J$ Med Internet Res. (2018) 20:e37. doi: 10.2196/jmir.8928

12. Ozguner F, Altinbas A, Ozaydin M, Dogan A, Vural H, Kisioglu AN, et al. Mobile phone-induced myocardial oxidative stress: protection by a novel antioxidant agent caffeic acid phenethyl ester. Toxicol Ind Health (2005) 21:223-30. doi: 10.1191/0748233705th228oa

13. Ortiz F, Fernandez-Gil BI, Guerra-Librero A. Preliminary evidence suggesting that nonmetallic and metallic nanoparticle devices protect against the effects of environmental electromagnetic radiation by reducing oxidative stress and inflammatory status. Eur J Integr Med. (2016) 8:835-40. doi: 10.1016/j.eujim.2016.06.009

14. Billieux J, Maurage P, Lopez-Fernandez O, Kuss DJ, Griffiths MD. Can disordered mobile phone use be considered a behavioral addiction? an update on current evidence and a comprehensive model for future research. Curr Addict Reports (2015) 2:156-62. doi: 10.1007/s40429-015-0054-y

15. Lin YH, Lin PH, Chiang CL, Lee YH, Yang CCH, Kuo TBJ, et al. Incorporation of Mobile Application (App) measures into the diagnosis of smartphone addiction. J Clin Psychiatry (2017) 78:866-72. doi: 10.4088/JCP.15m10310

16. Monney G, Penzenstadler L, Dupraz O, Etter JF, Khazaal Y. mHealth app for cannabis users: satisfaction and perceived usefulness. Front. Psychiatry (2015) 6:120. doi: $10.3389 /$ fpsyt.2015.00120

17. Ubhi HK, Michie S, Kotz D, Wong WC, West R. A mobile app to aid smoking cessation: preliminary evaluation of smokefree28. J Med Internet Res. (2015) 17:e17. doi: 10.2196/jmir.3479

18. Adams DA, Nelson RR, Todd PA. Perceived usefulness, ease of use, and usage of information technology - a replication. MIS Q. (1992) 16:227-47. doi: $10.2307 / 249577$

19. Melas CD, Zampetakis LA, Dimopoulou A, Moustakis V. Modeling the acceptance of clinical information systems among hospital medical staff: an extended TAM model. J Biomed Inform. (2011) 44:553-64. doi: 10.1016/j.jbi.2011.01.009
20. Holden RJ, Karsh BT. The technology acceptance model: its past and its future in health care. J Biomed Inform. (2010) 43:159-72. doi: 10.1016/j.jbi.2009.07.002

21. Gagnon MP, Ghandour el K, Talla PK, Simonyan D, Godin G, Labrecque $M$, et al. Electronic health record acceptance by physicians: Testing an integrated theoretical model. J Biomed Inform. (2014) 48:17-27. doi: 10.1016/j.jbi.2013.10.010

22. Deng Z, Mo X, Liu S. Comparison of the middle-aged and older users' adoption of mobile health services in China. Int J Med Inform. (2014) 83:21024. doi: 10.1016/j.ijmedinf.2013.12.002

23. Cimperman M, Brencic MM, Trkman P. Analyzing older users' home telehealth services acceptance behavior-applying an Extended UTAUT model. Int J Med Inform. (2016) 90:22-31. doi: 10.1016/j.ijmedinf.2016.03.002

24. Ebert DD, Berking M, Cuijpers P, Lehr D, Poertner M, Baumeister H. Increasing the acceptance of internet-based mental health interventions in primary care patients with depressive symptoms. A randomized controlled trial. J Affect Disord. (2015) 176:9-17. doi: 10.1016/j.jad.2015. 01.056

25. Clark LA, Watson D. Constructing validity: basic issues in objective scale development.. Psychol Assess. (1995) 7:309. doi: 10.1037/1040-3590.7.3.309

26. Price A. A Study of Factors Influencing Physician Adoption of Electronic Medical Records Technology [Dissertation]. Texas, TX: Grenoble Ecole de Management (2010).

27. Archer N, Cocosila M. A comparison of physician pre-adoption and adoption views on electronic health records in canadian medical practices. J Med Internet Res. (2011) 13:e57. doi: 10.2196/jmir.1726

28. Triandis HC. Values, attitudes, and interpersonal behavior. Nebr Symp Motiv. (1979) 27:195-259.

29. Hung SY, Tsai CA, Chuang CC. Investigating primary health care nurses' intention to use information technology: an empirical study in Taiwan. Decis Support Syst. (2014) 57:331-42. doi: 10.1016/j.dss.2013.09.016

30. Holden RJ. Social and personal normative influences on healthcare professionals to use information technology: towards a more robust social ergonomics. Theor Issues Ergon Sci. (2012) 13:546-69. doi: 10.1080/1463922X.2010.549249

31. Ketelaar PE, van Balen M. The smartphone as your follower: the role of smartphone literacy in the relation between privacy concerns, attitude and behaviour towards phone-embedded tracking. Comput Human Behav. (2018) 78:174-82. doi: 10.1016/j.chb.2017.09.034

32. Nov O, Schecter W. Dispositional resistance to change and hospital physicians' use of electronic medical records: a multidimensional perspective. J Am Soc Inf Sci Technol. (2012) 63:648-56. doi: 10.1002/asi. 22602

33. Hsiao JL, Chen RF. Critical factors influencing physicians' intention to use computerized clinical practice guidelines: an integrative model of activity theory and the technology acceptance model. BMC Med. Inform. Decis. Mak. (2016) 16:3. doi: 10.1186/s12911-016-0241-3

34. Baloglu M, Kozan HI, Kesici OS. Gender differences in and the relationships between social anxiety and problematic internet use: canonical analysis. J Med Internet Res. (2018) 20:e33. doi: 10.2196/jmir.8947

35. Ferreri F, Bourla A, Mouchabac S, Karila L. e-Addictology: an overview of new technologies for assessing and intervening in addictive behaviors. Front Psychiatry (2018) 9:51. doi: 10.3389/fpsyt.2018.00051

Conflict of Interest Statement: The authors declare that the research was conducted in the absence of any commercial or financial relationships that could be construed as a potential conflict of interest.

Copyright () 2018 Lee, Choi, Rho, Kim and Choi. This is an open-access article distributed under the terms of the Creative Commons Attribution License (CC BY). The use, distribution or reproduction in other forums is permitted, provided the original author(s) and the copyright owner(s) are credited and that the original publication in this journal is cited, in accordance with accepted academic practice. No use, distribution or reproduction is permitted which does not comply with these terms. 